\title{
Analisis Pengendalian Persediaan Material Scrap Besi Dengan Menggunakan Metode Algoritma Wagner Within Pada PT Purna Sentana \\ Baja
}

\author{
Amri Yanuar ${ }^{1}$ ), Yanita Carolina ${ }^{2}$ ) \\ 1 D4 Logistik Bisnis Politeknik Pos Indonesia \\ email: amriyanuar@poltekpos.ac.id \\ ${ }_{2}$ D4 Logistik Bisnis Politeknik Pos Indonesia \\ email: yanitacorina21@gmail.com
}

\begin{abstract}
Abstrak
Pengadaan barang dan jasa perusahaan sangat besar pengaruhnya karena akan berkaitan dengan menjaga kelangsungan proses produksi. Salah satu yang menjadi hal terpenting adalah pengendalian ketersediaan raw material produksi. PT Purna Sentana Baja merupakan sebuah perusahaan perdagangan yang menyediakan produk-produk raw material untuk industri besi dan baja. Salah satu produk raw material yang akan diteliti yaitu produk material scrap besi. Permasalahan yang terjadi yaitu kebijakan inventory perusahaan yang masih bersifat tradisional dengan belum adanya suatu metode yang digunakan oleh perusahaan dalam penentuan ukuran pemesanan barang yang mengakibatkan terjadinya kelebihan persediaan barang. Penelitian ini mengusulkan metode pengendalian persediaan dengan Algoritma Wagner Within untuk menentukan jumlah pemesanan atau ukuran lot pemesanan dan waktu pemesanan yang optimal. Peramalan permintaan material scrap besi menggunakan metode peramalan MA, WMA, dan ES. Hasil perhitungan metode Algoritma Wagner Within memperoleh biaya total persediaan sebesar Rp. 202.306.771.680 dan total biaya tersebut lebih optimal jika dibandingkan dengan total biaya persediaan dengan sistem perusahaan yaitu sebesar Rp. 209.317.771.680. Berdasarkan perbandingan total biaya tersebut perusahaan dapat menghemat biaya sebesar Rp. 7.011.000.000.
\end{abstract}

\section{Kata Kunci: Pengendalian Persediaan, Peramalan, Algoritma Wagner Within}

\section{PENDAHULUAN}

Perencanaan kebutuhan perusahaan terkait barang atau jasa yang diperlukan harus dirancang dengan matang agar dapat mengurangi risiko kegagalan yang mungkin terjadi. Barang dan jasa dapat diperoleh dengan melakukan rencana pengadaan dengan mempertimbangkan jenis barang atau jasa yang dibutuhkan, jumlah kebutuhan, dan kapan waktu dibutuhkannya barang dan jasa tersebut sehingga perencanaan kebutuhan dapat dikendalikan. Pengendalian terhadap pengadaan barang dan jasa perusahaan sangat besar pengaruhnya karena akan berkaitan dengan menjaga kelangsungan proses produksi. Salah satu yang menjadi hal terpenting adalah pengendalian ketersediaan bahan baku yang terkadang memberikan persoalan tersendiri bagi suatu perusahaan sehingga membutuhkan adanya suatu bagian atau melakukan outsourcing untuk melakukan kegiatan pengadaan tersebut. Salah satu perusahaan atau instansi yang bergerak sebagai penyedia jasa pengadaan barang dan jasa adalah perusahaan trading yaitu salah satunya

PT Purna Sentana Baja. Salah satu produk trading yang dimiliki yaitu scrap besi yang menjadi bahan baku utama yang penting bagi industri besi dan baja. Kondisi yang saat ini terjadi pada perusahaan yaitu kebijakan inventory perusahaan yang masih bersifat tradisional dengan belum adanya suatu metode yang 
digunakan oleh perusahaan dalam penentuan ukuran pemesanan barang yang mengakibatkan terjadinya kelebihan persediaan barang.

Adanya beberapa penelitian terdahulu yang dijadikan sebagai dasar dan acuan dari penelitian ini yaitu penelitian oleh Maulana dan Setyorini (2015) Penelitian ini bertujuan untuk mengendalikan persediaan bahan baku dengan menggunakan pendekatan metode lot sizing Algoritma Wagner Within (AWW) dan lot-for-lot (LFL). Perhitungan dengan metode lot sizing ini akan diketahuinya jumlah dan waktu pemesanan yang optimal.

Maitimu dan Peea (2017) mengusulkan metode pengendalian persediaan dengan teknik Algoritma Wagner Within. Metode Algoritma Wagner Within ini untuk penentuan ukuran lot dan waktu pemesanan yang optimal, dengan menghasilkan total biaya paling minimum.

Tujuan dari penelitian ini yaitu untuk melakukan analisa pengendalian persediaan material scrap besi dengan menggunakan metode Algoritma Wagner Within, yang dimana sebelumnya pada perusahaan belum menerapkan metode pengendalian persediaan yang mengakibatkan terjadinya kelebihan dan kekurangan barang. Sehingga penelitian ini dengan menggunakan metode usulan Algoritma Wagner Within bertujuan untuk memberikan analisa mengenai jumlah pemesanan, frekuensi pemesanan, dan mengetahui total biaya persediaan perusahaan. Harapan dari penelitian ini yaitu dapat memberikan usulan mengenai pengendalian persediaan untuk perusahaan yang sebelumnya belum diterapkan dengan dapat memperoleh penghematan biaya persediaan dan dengan harapan penelitian dapat dijadikan sebagai referensi untuk kedepannya.

\section{METODE PENELITIAN}

Metode usulan untuk pengendalian persediaan material scrap besi yaitu metode Algoritma Wagner Within untuk mengetahui jumlah pemesanan dan frekuensi pemesanaan sehingga dapat diperoleh biaya persediaan yang optimal dengan metode peramalan MA, WMA, dan
ES dan kesalahan peramalan dengan metode MAD, MSE, dan MAP. Adapun rancangan analisis penelitian ini yaitu:

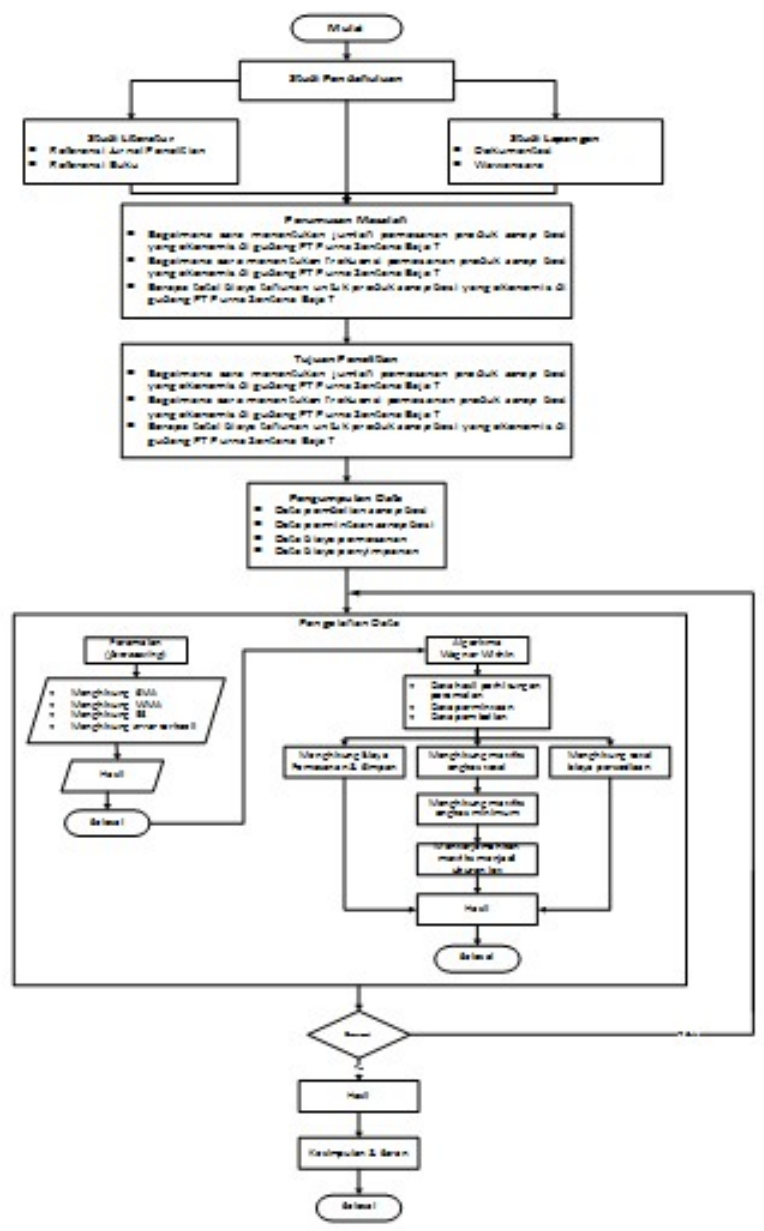

Gambar 1: Rancangan Analisis Penelitian

Metode pengumpulan data yang digunakan dalam penelitian ini yaitu:

1. Studi kepustakaan, yaitu teknik pengumpulan data atau informasi dengan cara membaca referensi, buku, artikel, jurnal dan skripsi yang ada hubungannya dengan landasan teori dan metode penelitian yang akan penulis gunakan dalam menyelesaikan permasalahan. Studi kepustakaan yang dilakukan penulis yaitu untuk mendapatkan referensi mengenai permasalahan yang diteliti dengan penerapan metode yang sesuai dengan permasalahan yang akan diteliti berdasarkan penelitian terdahulu.

2. Wawancara, yaitu teknik pengumpulan data atau informasi yang dilakukan untuk menemukan masalah yang akan diteliti yang dapat dilakukan secara terstruktur atau tidak tersruktur dan dapat

Page | 79 
dilakukan dengan melalui tatap muka atau dengan menggunakan alat komunikasi (telepon).

\section{HASIL DAN PEMBAHASAN}

Data-data yang dibutuhkan terkait dengan metode pemecahan masalah Algoritma Wagner Within, yaitu:

Data permintaan scrap besi. Data permintaan berikut ini merupakan data permintaan material scrap besi pada tahun 2018. Data permintaan ini akan dijadikan sebagai acuan untuk melakukan peramalan periode selanjutnya dengan menggunakan metode peramalan yang telah pilih yaitu MA, WMA, dan ES. Adapun data permintaan material scrap besi, yaitu:

Tabel 1: Data Permintaan Scrap Besi

\begin{tabular}{|c|c|c|}
\hline \multicolumn{3}{|c|}{ Periode 2018} \\
\hline No & Bulan & Permintaan (Ton) \\
\hline 1 & Januari & 2.393 \\
\hline 2 & Februari & 2.822 \\
\hline 3 & Maret & 3.575 \\
\hline 4 & April & 2.274 \\
\hline 5 & Mei & 2.250 \\
\hline 6 & Juni & 1.245 \\
\hline 7 & Juli & 1.433 \\
\hline 8 & Agustus & 2.376 \\
\hline 9 & September & 3.190 \\
\hline 10 & Oktober & 3.149 \\
\hline 11 & November & 3.647 \\
\hline 12 & Desember & 2.248 \\
\hline & Total & 30.602 \\
\hline
\end{tabular}

Harga per kilo scrap besi yang digunakan akan diasumsikan sama atau tidak mengalami perubahan harga untuk tahun berikutnya. Adapun harga per kilo scrap besi adalah Rp. 5.700/kilo.

\section{Peramalan Permintaan Scrap Besi}

Perhitungan peramalan dan kesalahan peramalan ini akan menggunakan bantuan software POM QM. Adapun hasil perhitungan peramalan dan kesalahan peramalan, yaitu:

\begin{tabular}{|c|c|c|c|c|c|c|}
\hline (1) & \multicolumn{4}{|c|}{ Details and Error Analysis } & \multicolumn{2}{|c|}{$0 \quad 0 \quad x$} \\
\hline \multicolumn{7}{|c|}{ forecast solution } \\
\hline & Demand(y) & Forecast & Error & |Error| & Error'2 & |Pct Error| \\
\hline January & 2393 & & & & & \\
\hline February & 2822 & & & & & \\
\hline March & 3575 & & & & & \\
\hline April & 2274 & 2930 & -656 & 656 & 430336 & 29 \\
\hline May & 2250 & 2890,33 & $-640,33$ & 640,33 & 410026,7 &, 28 \\
\hline June & 1245 & 2699,67 & $-1454,67$ & 1454,67 & 2116055,0 & 1,17 \\
\hline July & 1433 & 1923 & -490 & 490 & 240100 & 34 \\
\hline August & 2376 & 1642,67 & 733,33 & 733,33 & 537777,8 &, 31 \\
\hline September & 3190 & 1684,67 & 1505,33 & 1505,33 & 2266029,0 &, 47 \\
\hline October & 3149 & 2333 & 816 & 816 & 665856 &, 26 \\
\hline November & 3647 & 2905 & 742 & 742 & 550564 & 2 \\
\hline December & 2248 & 3328,67 & $-1080,67$ & 1080,67 & 1167840,0 &, 48 \\
\hline TOTALS & 30602 & & -525 & 8118,33 & 8384584 & 3,81 \\
\hline AVERAGE & 2550,17 & & $-58,33$ & 902,04 & 931620,4 &, 42 \\
\hline \multirow[t]{2}{*}{ Next period forecast } & & 3014,67 & (Bias) & (MAD) & (MSE) & (MAPE) \\
\hline & & & & Std err & 1094,44 & \\
\hline (1) & \multicolumn{4}{|c|}{ Details and Error Analysis } & 口 & (1) $x$ \\
\hline \multicolumn{7}{|c|}{ forecast solution } \\
\hline & Demand(y) & Forecast & Error & |Errori| & Error'2 & |Pct Error) \\
\hline January & 2393 & & & & & \\
\hline February & 2822 & & & & & \\
\hline March & 3575 & & & & & \\
\hline April & 2274 & 3127 & .853 & 853 & 727609 &, 38 \\
\hline May & 2250 & 2799 & .549 & 549 & 301401 & .24 \\
\hline June & 1245 & 2478,83 & $-1233,83$ & 1233,83 & 1522345,0 & 1 \\
\hline July & 1433 & 1751,5 & $-318,5$ & 318,5 & 101442,3 & .22 \\
\hline August & 2376 & 1506,5 & 869,5 & 869,5 & 756030,3 &, 37 \\
\hline September & 3190 & 1873,17 & 1316,83 & 1316,83 & 1734050,0 &, 41 \\
\hline October & 3149 & 2625,83 & 523,17 & 523,17 & 273703,4 &, 17 \\
\hline November & 3647 & 3033,83 & 613,17 & 613,17 & 375973,5 &, 17 \\
\hline December & 2248 & 3404,83 & $-1156,83$ & 1156,83 & 1338264,0 &, 51 \\
\hline TOTALS & 30602 & & $.788,5$ & 7433,83 & 7130818 & 3,46 \\
\hline AVERAGE & 2550,17 & & $-87,61$ & 825,98 & 792313,1 &, 38 \\
\hline \multirow[t]{2}{*}{ Next period forecast } & & 2864,5 & (Bias) & (MAD) & (MSE) & (MAPE) \\
\hline & & & & Std err & 1009,3 & \\
\hline
\end{tabular}

Gambar 3: Solusi Peramalan WMA Pembobotan 3 Bulan

\section{Metode Exponential Smoothing (ES)}

Peramalan menggunakan metode ES ini membutuhkan adanya suatu nilai $\alpha$. Menurut Fogarty (1991:94), untuk menentukan nilai $\alpha$ dapat menggunakan rumus sebagai berikut:

$$
\begin{aligned}
& \alpha=\frac{2}{N+1} \\
& \alpha=\frac{2}{2}=0,153 \approx 0,2
\end{aligned}
$$




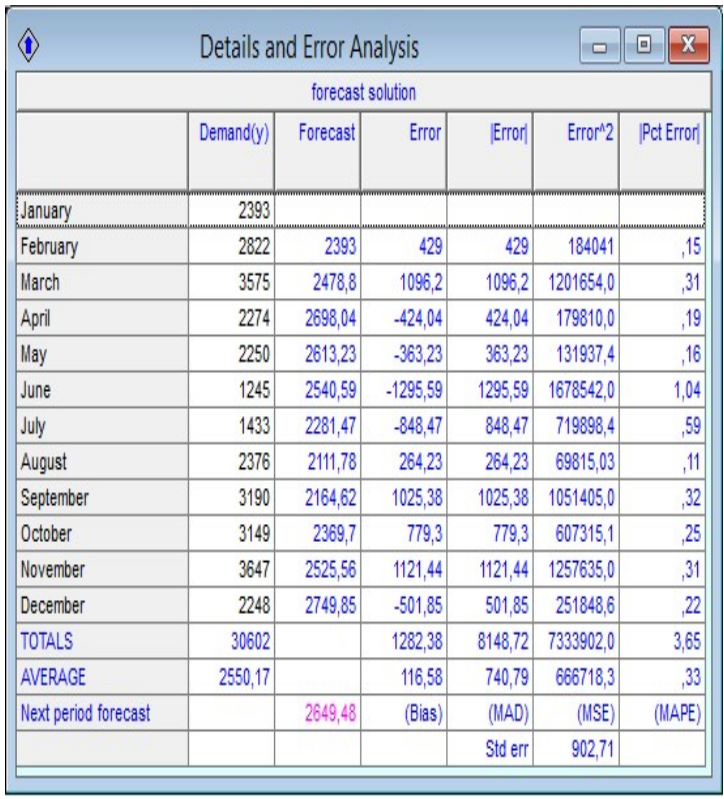

\section{Gambar 4: Solusi Peramalan ES $\propto 0.2$}

Berdasarkan perhitungan peramalan dan kesalahan peramalan menggunakan software POM QM, maka dapat dibuat gambaran dalam bentuk tabel untuk nantinya dapat diketahui nilai error yang terkecil. Adapun nilai-nilai tersebut dapat dilihat pada tabel berikut:

\section{Tabel 2: Kalkulasi Nilai Peramalan}

\begin{tabular}{|c|c|c|c|c|}
\hline Deskripsi & $\begin{array}{c}\text { Nilai } \\
\text { MAD }\end{array}$ & $\begin{array}{c}\text { Nilai } \\
\text { MSE }\end{array}$ & $\begin{array}{c}\text { Nilai } \\
\text { MAPE }\end{array}$ & Keputusan \\
\hline $\begin{array}{c}\text { MA } \\
\text { n-periode 3 }\end{array}$ & 902,04 & 931620,4 &, 42 & \\
\hline $\begin{array}{c}\text { WMA } \\
\text { Pembobotan } \\
3 \text { bulan }\end{array}$ & 825,98 & 792313,1 &, 38 & \\
\hline $\begin{array}{c}\text { ES } \\
\alpha 0.2\end{array}$ & 740,79 & 666718,3 &, 33 & Menerima \\
\hline
\end{tabular}

Berdasarkan deskripsi kalkulasi nilai diatas maka dapat dilihat perbandingan model peramalan yang digunakan. Pemilihan metode peramalan yang akan digunakan yaitu dengan melihat nilai error yang terkecil dari ketiga metode tersebut. Dilihat dari tabel diatas maka akan dipilih metode ES $\alpha 0.2$ karena memiliki nilai error terkecil dan forecast yang ada dalam ES $\alpha 0.2$ akan digunakan sebagai data untuk menghitung dengan metode Algoritma Wagner Within.

\section{Analisa Hasil}

Menentukan perencanaan dan pengendalian persediaan sebelumnya perusahaan hanya berdasarkan atas perkiraan dan pembelian secara terus menerus sehingga menyebabkan kondisi kelebihan barang pada gudang. Perbandingan total biaya persediaan antara kondisi existing perusahaan yang belum menggunakan metode pengendalian persediaan dengan biaya persediaan dengan metode pengendalian persediaan Algoritma Wagner Within.

Harga bahan baku sebesar Rp. 5.700/kg, maka ongkos total untuk kondisi existing dan metode Algoritma Wagner Within, yaitu:

a. Sistem Inventory Perusahaan

$$
\begin{aligned}
T= & (30.602 .000 \text { kilo } x \text { Rp. } 5.700)+(12 \times \text { Rp. } 7.640) \\
& +(30.602 .000 \text { kilo } x \text { Rp. } 1.140) \\
= & \text { Rp. } 174.431 .400 .000+\text { Rp. } 91.680 \\
& + \text { Rp. } 34.886 .280 .000 \\
= & \text { Rp. } 209.317 .771 .680
\end{aligned}
$$

b. Metode Algoritma Wagner Within

$$
\begin{aligned}
T= & (29.577 .000 \text { kilo } x \text { Rp. } 5.700)+(12 \times \text { Rp. } 7.640) \\
& +(29.577 .000 \text { kilo } x \text { Rp. } 1.140) \\
= & \text { Rp. } 168.588 .900 .000+\text { Rp. } 91.680 \\
& + \text { Rp. } 33.717 .780 .000 \\
= & \text { Rp. } 202.306 .771 .680
\end{aligned}
$$

Berdasarkan perhitungan biaya total diatas, dapat dilihat adanya penurunan biaya inventory yang dilihat dari total biaya inventory untuk sistem yang digunakan oleh perusahaan jika dibandingkan dengan hasil dari total biaya inventory menggunakan metode Algoritma Wagner Within, maka dapat dilihat hasil perbandingan total biaya inventory dari kedua sistem sebagai berikut:

Tabel 3: Perbandingan Hasil Biaya Inventory

\begin{tabular}{|c|c|c|c|}
\hline & $\begin{array}{c}\text { Existing } \\
\text { Perusahaan }\end{array}$ & $\begin{array}{c}\text { Algoritma } \\
\text { Wagner Within }\end{array}$ & Penghematan \\
\hline Total Biaya & $\mathrm{Rp.}$ & $\mathrm{Rp}$. & $\mathrm{Rp.}$ \\
Inventory & 209.317 .771 .680 & 202.306 .771 .680 & 7.011 .000 .000 \\
\hline
\end{tabular}


Berdasarkan tabel di atas dapat dilihat bahwa metode Algoritma Wagner Within dengan total biaya inventory Rp. 202.306.771.680 lebih optimal jika dibandingkan dengan sistem yang saat ini.

\section{KESIMPULAN}

Berdasarkan analisis permasalahan dan pengolahan data yang telah dilakukan, maka dapat ditarik kesimpulan mengenai pengendalian persediaan dengan menggunakan metode Algoritma Wagner Within. Berdasarkan hasil analisis dan pengolahan data, maka dapat disimpulkan:

1. Perhitungan metode Algoritma Wagner Within ini menghasilkan total ukuran lot pemesanan material scrap besi lebih kecil jika dibandingkan dengan ukuran lot pemesanan sebelumnya yang tanpa menggunakan peramalan dan penggunaan metode pengendalian persediaan yaitu sebesar 29.577 ton per tahun dengan frekuensi pemesanan sebanyak 12 kali dalam waktu 12 periode.

2. Total biaya inventory perusahaan sebelum melakukan peramalan dan penggunaan metode pengendalian persediaan adalah Rp. 209.317.771.680, dan total biaya inventory setelah melakukan peramalan dan penggunaan metode pengendalian persediaan menjadi turun yaitu sebesar Rp. 202.306.771.680. Perusahaan dapat memperoleh penghematan biaya sebesar Rp.7.011.000.000 per tahun untuk material scrap besi.

Perusahaan harus bisa mengendalikan persediaan barangnya agar tidak mengalami kelebihan dan kekurangan stok. Melihat kondisi saat ini yaitu perusahaan mengalami kelebihan persediaan dan dampaknya yaitu perusahaan harus mengeluarkan biaya lebih untuk penyimpanannya yang sebenarnya jika menggunakan peramalan dan pengendalian persediaan biaya tersebut bisa diminimalisir. Perusahaan perlu menggunakan dan menerapkan metode pengendalian persediaan yaitu salah satunya metode Algoritma Wagner Within untuk bisa melakukan pengendalian persediaan serta mengetahui jumlah pemesanan dan waktu pemesanan yang tepat dan dilihat dari penelitian ini perusahaan dapat menghemat biaya persediaan.

\section{REFERENSI}

Jurnal:

Maitimu, N.E dan Meirlin S. Peea. 2017. Penentuan Ukuran Lot Pemesanan Optimal Bahan Baku Ikan Tuna Dengan Model Dinamis Algoritma WagnerWithin Dalam Upaya Minimasi Ongkos Total Persediaan (Studi Kasus : PT Mina Maluku Sejahtera). Jurnal Arika, Vol. 11 No.1.

Maulana, Lundy dan Retno Setyorini. 2015. Perencanaan Kebutuhan Bahan Baku Produk Windlass Dengan Menggunakan Metode Lot Sizing Pada PT Pindad (Persero). Jurnal Universitas Telkom.

\section{Texbooks:}

Bahagia, Senator Nur. 2006. Sistem Inventori. Bandung: Penerbit ITB.

Fogarty, Donald W. 1991. Production And Inventory Control. America. South-Western Publishing Co.

Heizer, Jay dan Barry Render. 2006. Operation Management, Edisi Ketujuh, diterjemahkan oleh Dwianoegrahwati Setyoningsih, M.Eng.Sc dan Indra Almahdy, M.Sc. Jakarta: Penerbit Salemba Empat.

Indrajit, Richardus Eko dan Djokopranoto Richardus. 2005. Manajemen Persediaan. Jakarta: PT Grasindo.

Prasetya, Hery dan Fitri Lukiastuti. 2009. Manajemen Operasi. Yogyakarta: Media Pressindo.

Ristono, Agus. 2013. Manajemen Persediaan. Yogyakarta: Graha Ilmu.

Sugiyono. 2013. Metode Penelitian Manajemen. Jakarta: Alfabeta. 